\title{
Brief Report \\ Impact of COVID-19 Pandemic on (Health) Care Situation of People with Parkinson's Disease in Germany (Care4PD)
}

\author{
Odette Fründt ${ }^{1, *}$, Anne-Marie Hanff ${ }^{2}{ }^{\oplus}$, Tobias Mai ${ }^{3}{ }^{\oplus}$, Christiane Kirchner $^{1}$, Emma Bouzanne des Mazery ${ }^{1}$, \\ Ali Amouzandeh ${ }^{1}$, Carsten Buhmann ${ }^{4}$, Rejko Krüger ${ }^{2,5,6}$ () and Martin Südmeyer ${ }^{1,7}$
}

1 Department of Neurology, Klinikum Ernst von Bergmann, Charlottenstraße 72, 14467 Potsdam, Germany; christiane.kirchner@klinikumevb.de (C.K.); Emma.BouzannedesMazery@klinikumevb.de (E.B.d.M.); ali.amouzandeh@klinikumevb.de (A.A.); Martin.Suedmeyer@klinikumevb.de (M.S.)

2 Transversal Translational Medicine, Luxembourg Institute of Health (LIH), 1A-B, Rue Thomas Edison, L-1445 Luxembourg, Luxembourg; Anne-Marie.Hanff@lih.lu (A.-M.H.); rejko.krueger@uni.lu (R.K.)

3 Department of Nursing Development/Nursing Research, University Hospital Frankfurt, Theodor-Stern-Kai 7, 60590 Frankfurt, Germany; Tobias.Mai@kgu.de

4 Department of Neurology, University Medical Center Hamburg-Eppendorf, Martinistraße 52, 20246 Hamburg, Germany; buhmann@uke.de

5 Luxembourg Centre for Systems Biomedicine (LCSB), University of Luxembourg, 6, Avenue du Swing, L-4367 Luxembourg, Luxembourg

6 Parkinson Research Clinic, Centre Hospitalier de Luxembourg (CHL), 4, Rue Nicolas Ernest Barblé, L-1210 Luxembourg, Luxembourg

7 Department of Neurology, University Medical Center Düsseldorf, Moorenstraße 5, 40225 Düsseldorf, Germany

* Correspondence: odette.fruendt@klinikumevb.de; Tel.: +49-331-241-37102

\section{check for}

updates

Citation: Fründt, O.; Hanff, A.-M.;

Mai, T.; Kirchner, C.; Bouzanne des

Mazery, E.; Amouzandeh, A.;

Buhmann, C.; Krüger, R.; Südmeyer, M. Impact of COVID-19 Pandemic on (Health) Care Situation of People with Parkinson's Disease in Germany (Care4PD). Brain Sci. 2022, 12, 62. https://doi.org/10.3390/ brainsci12010062

Academic Editor: Carla Masala

Received: 3 December 2021

Accepted: 27 December 2021

Published: 31 December 2021

Publisher's Note: MDPI stays neutral with regard to jurisdictional claims in published maps and institutional affiliations.

Copyright: (c) 2021 by the authors. Licensee MDPI, Basel, Switzerland. This article is an open access article distributed under the terms and conditions of the Creative Commons Attribution (CC BY) license (https:// creativecommons.org/licenses/by/ $4.0 /)$.

\begin{abstract}
The Care4PD study examined the impact of the COVID-19 pandemic on the care situation of people (PwP) with Parkinson's disease in Germany. A comprehensive, nationwide, anonymous questionnaire for PwP was distributed by the members' journal of the German Parkinson's Disease Association and in several PD specialized in- and outpatient institutions. PwP subjectively evaluated their general care situation and individual impairments during the pandemic. We analyzed 1269 eligible out of 1437 returned questionnaires (88.3\%) and compared PwP with (p-LTC) and without (np-LTC) professional long-term care. Both groups rated the general pandemic-related consequences as being rather mild to moderate (e.g., worsening of symptom or concerns). However, familial/social contact restrictions were indicated as most compromising, whereas access to outpatient professional health care providers was less affected. PwP with professional LTC reported more impairment than those without. COVID-19 vaccination rates and acceptance were generally high (p-LTC: 64.3\%, npLTC: $52.3 \%$ ) at the time of the study, but realization of sanitary measures-especially wearing masks as a patient during care sessions-still needs to be improved. Technical options for telemedicine were principally available but only rarely used. Altogether, during the COVID-19 pandemic, PwP in Germany seemed to have a relatively stable health care access, at least in outpatient settings, while mainly social isolation compromised them. The p-LTC group was more impaired in everyday live compared with the np-LTC group.
\end{abstract}

Keywords: Parkinson's disease; corona; COVID-19; care; Germany; impact; impairments; telemedicine; Care4PD; vaccination

\section{Introduction}

Data are inconclusive on whether the diagnosis of Parkinson's Disease (PD) is a specific risk factor for a negative COVID-19 outcome [1-7] or whether a COVID-19 infection itself could cause a neurodegenerative disease such as PD [8-11]. The International Parkinson and Movement Disorder Society published a viewpoint with behavioral recommendationsindependent of the general social restrictions to prevent the viral spread-such as strictly 
practicing social distancing, avoiding in-hospital stays for non-emergency reasons, postponing elective DBS surgery, and using telemedicine instead of direct outpatient visits [1]. In addition to these suggestions and the general limitations, disruptions of everyday activities and reduced access to health care and therapists might further complicate the situation of people with Parkinson's disease (PwP) during the COVID-19 pandemic. Global and regional studies from America (US, Canada, Brazil), Asia (China, Japan, South Korea, India, Iran Israel, Turkey), North Africa (Egypt), or European countries (Luxembourg, Netherlands, UK, Italy, Spain, Slovenia) reported wide-ranging consequences of the pandemic on PwP, such as worsened motor and non-motor symptoms [12-28], a negative impact on mental health [29], a decline in quality of life [20,21,30], disrupted social and medical activities [12,13], impaired access to PD medication [21,31,32], or other unmet needs such as emotional distress, problems with rescheduling appointments with health care providers, and reduction in physical activity $[2,14,20,22,24,33,34]$. On the other side, although hours of caregiving at home and caregiver burden increased [33], patients and caregivers seem to be well informed and to have coped well in some studies [35-37].

To our knowledge there are currently only two studies published examining the impact of the COVID-19 pandemic on PwP in Germany, either focusing on knowledge, attitudes, and preventive behavior of $\mathrm{PwP}$ during the pandemic [38] or on the decline in PD multimodal complex treatment and application of pump-based therapies [39]. As part of the comprehensive, nationwide Care4PD patient survey, we here explicitly examine the impact of the COVID-19 pandemic on the real-word health care situation of PwP in general and with special focus on long-term care in Germany - a field that has only attracted little scientific attention nationally and internationally as of yet [40].

\section{Materials and Methods}

The Care4PD patient survey (available at [41]) was developed to evaluate the care situation of PwP in Germany in general (part I) and of those PwP employing professional long-term care (LTC) services (part II) such as outpatient care services, professional domestic 24-h care by external care staff or nursing homes. In addition to demographic and diseaserelated questions, the current care situation of $\mathrm{PwP}$ (e.g., use of professional care, care degree, availability of house calls, support in everyday life, etc.) and the impact of the COVID-19 pandemic on the individual care situation were investigated.

A testing phase of the initial questionnaire draft comprised interviews with ten PwP and their caregivers, with a specialist in gerontology experienced in the field of barrierfree accessibility, with several movement disorders specialists, and with a statistician. Afterwards, the questionnaire was revised, condensed, and optimized to the final version. This finally included 56 questions in total, with 13 COVID-specific questions (part I: 10, part II: 3) that are attached as Supplementary Materials. Single or multiple-choice questions, visual analogue scales (from $0=$ not applicable/not at all to $10=$ very applicable/very much), and open questions were used.

Questionnaires were distributed nationwide using the members' journal of the German Parkinson Association (Deutsche Parkinson Vereinigung e.V., dPV) and via post in several PD specialized in- and outpatient institutions, with a circulation of about 25,000 copies. Study participation was voluntary and anonymous. The study was approved by the local ethics committee (reference: S10(bB)/2021). The questionnaire was deployed and collected from March to July 2021.

Returned questionnaires $(n=1437$, response rate about $5.7 \%$ ) were scanned and automatically recorded in a database using FormPro 3.0 software by OCR Systeme GmbH [42]. The quality of this automatic database feeding was good with a rate of only $3.5 \pm$ SD 4.8 (0-60) misreading, mainly regarding detection of handwriting in free text questions or of very small or faint ticks. Throughout, the data base was supervised, manually checked for plausibility, and later imported into IBM SPSS ${ }^{\circledR}$ Statistics version 27 [43] to perform statistical analysis. Questionnaires that were sent twofold $(n=1)$, with inconsistent answers $(n=115)$ or $>30 \%$ missing data $(n=52)$, were excluded from analysis. 
Student's t-test was used for group comparisons of metrical variables between PwP with ("p-LTC" group) and without professional long-term care ("np-LTC" group). Corrected $p$-values were used in cases with unequal variances. Nominal or ordinal variables were compared between groups using Pearson's chi-squared test.

In this short communication, the main demographic and COVID-19-related results of the Care4PD survey are reported.

\section{Results}

Finally, a total of 1269 out of 1437 questionnaires (88.3\%) was analyzed, including 269 PwP with (21\%, p-LTC) and 1000 PwP without (79\%, np-LTC) professional long-term care.

\subsection{Demographic and Clinical Data}

Demographic and clinical data are shown in Table 1 separately for both groups (p-LTC vs. np-LTC). PwP with p-LTC were mainly cared for by outpatient care services (62.1\%), followed by residing in nursing homes $(26.0 \%)$ and those supplied by professional $24-\mathrm{h}$ care $(11.9 \%)$.

Compared with np-LTC PwP, those receiving professional care were older, predominantly female, scored higher in the Hoehn and Yahr stage, indicating greater disease severity, had a higher mean care degree, and were hospitalized more often for emergency or non-emergency reasons during the pandemic. Infection rates (5.5\% vs. 1.7\%) but also vaccination rates against SARS-CoV-2 (at least one vaccination at the time of the study from March to July 2021: 64.3\% vs. 52.3\%) were higher in PwP with p-LTC compared with the np-LTC group.

Although a great number of PwP (85.5\% in the p-LTC and with 92.6\% even significantly more PwP in the np-LTC group) would have the technical options to perform telemedicine (internet, telephone, or both combined), utilization of telemedicine in principle was only conceivable in about 50\% of PwP in both groups. During the COVID-19 pandemic, on a scale from 0 (not at all) to 10 (very frequently), the actual use of telemedicine was reported to be rather seldom (mean of 2.8 in the p-LTC and 3.1 in the np-LTC group, $p=0.263$ ) in both groups. There was no significant difference in the use, willingness or technical options between PwP in less populated ( $<20,000$ inhabitant) and densely populated areas $(>20,000$ inhabitants, all $p>0.05)$.

\subsection{Comparison of the Pandemics' General Consequences and Care-Related Impairments between $p$-LTC and $n p-L T C$}

General consequences of the COVID-19 pandemic on PwPs' lives were rated on a visual scale from 0 (not applicable/not at all) to 10 (very applicable/very much; see Supplementary Materials). Results are shown in Figure 1.

Summarizing Figure 1, the COVID-19 pandemic resulted in only mild worsening of PD symptoms and only a few phases in which PwP felt less supported during the pandemic. Concerns about the pandemic and its impact on everyday life were rated as moderate in both groups. All consequences were more pronounced in the p-LTC group, with significant group differences for symptom worsening $(p<0.001)$, decrease in support $(p<0.001)$, and overall impact on everyday life $(p=0.043)$.

Regarding specific, care-related consequences during the pandemic, a greater proportion of the np-LTC group (27.8\%) reported no impairment at all compared with those with p-LTC $(14.9 \%, p<0.001$, see Figure 2, left graph). 
Table 1. Demographic and clinical data of people with Parkinson's disease with (p-LTC) and without (np-LTC) professional long-term care.

\begin{tabular}{|c|c|c|c|c|c|}
\hline Parameter & $\begin{array}{c}\text { p-LTC }(n=269) \\
(\text { Mean }(\text { Min-Max }) \pm \text { SD) }\end{array}$ & & $\begin{array}{c}\text { np-LTC }(n=1000) \\
(\text { Mean }(\text { Min-Max }) \pm \text { SD) }\end{array}$ & & $\begin{array}{l}\text { Statistics } \\
(p \text {-Value) }\end{array}$ \\
\hline Residence & $\begin{array}{c}<20,000 \text { inhabitants: } 39.4 \% \\
>20,000 \text { inhabitants: } 56.1 \% \\
\text { (n.a.: } 4.5 \% \text { ) }\end{array}$ & $\begin{array}{l}n=106 \\
n=151 \\
n=12\end{array}$ & $\begin{array}{c}<20,000 \text { inhabitants: } 39.4 \% \\
>20,000 \text { inhabitants: } 56.9 \% \\
\text { (n.a.: } 3.7 \% \text { ) }\end{array}$ & $\begin{array}{l}n=394 \\
n=569 \\
n=37\end{array}$ & $p=0.924$ \\
\hline Gender & $\begin{array}{c}\sigma^{\top} 46.9 \% \\
\text { } 52.4 \% \\
\text { (n.a.: } 0.7 \%)\end{array}$ & $\begin{array}{c}n=126 \\
n=141 \\
n=2\end{array}$ & $\begin{array}{c}\text { o }^{\prime} 55.1 \% \\
\text { } 43.8 \% \\
\text { (n.a.: } 1.1 \%)\end{array}$ & $\begin{array}{c}n=551 \\
n=438 \\
n=11\end{array}$ & $p=0.013$ \\
\hline Age (years) & $76.5(48-95) \pm$ SD 8.0 & $n=265$ & $71.5(42-97) \pm$ SD 8.6 & $n=988$ & $p<0.001$ \\
\hline $\begin{array}{l}\text { Age at diagnosis } \\
\text { (years) }\end{array}$ & $63.2(22-87) \pm$ SD 11.1 & $n=255$ & $62.0(32-87) \pm$ SD 10.3 & $n=990$ & $p=0.099$ \\
\hline Hoehn and Yahr stage & $\begin{array}{c}.8(1-5) \pm \text { SD } 1.0 \\
\text { H\&Y1: } 3.7 \% \\
\text { H\&Y2: } 3.3 \% \\
\text { H\&Y3: } 22.3 \% \\
\text { H\&Y4: } 35.0 \% \\
\text { H\&Y5: } 24.2 \% \\
\text { (n.a.: } 11.5 \%)\end{array}$ & $\begin{array}{c}n=238 \\
n=10 \\
n=9 \\
n=60 \\
n=94 \\
n=65 \\
n=31\end{array}$ & $\begin{array}{c}2.8(1-5) \pm \text { SD } 1.1 \\
\text { H\&Y1: } 18.9 \% \\
\text { H\&Y2: } 9.2 \% \\
\text { H\&Y3: } 43.6 \% \\
\text { H\&Y4: } 19.8 \% \\
\text { H\&Y5: } 3.1 \% \\
\text { (n.a.: } 5.4 \%)\end{array}$ & $\begin{array}{c}n=946 \\
n=189 \\
n=92 \\
n=436 \\
n=198 \\
n=31 \\
n=54\end{array}$ & $p<0.001$ \\
\hline Care degree $^{\circ}$ & $\begin{array}{c}3.2(1-5) \pm \text { SD } 1.1 \\
\text { None: } 1.1 \% \\
\text { Degree 1: } 5.6 \% \\
\text { Degree 2: } 23.1 \% \\
\text { Degree 3: } 32.3 \% \\
\text { Degree 4: } 26.0 \% \\
\text { Degree 5: } 11.5 \% \\
\text { Don't know: } 0.4 \% \\
\text { (n.a.: } 0 \% \text { ) }\end{array}$ & $\begin{array}{c}n=269 \\
n=3 \\
n=15 \\
n=62 \\
n=87 \\
n=70 \\
n=31 \\
n=1 \\
n=0\end{array}$ & $\begin{array}{c}2.5(1-5) \pm \text { SD } 0.9 \\
\text { None: } 54.0 \% \\
\text { Degree 1: } 6.0 \% \\
\text { Degree 2: } 16 \% \\
\text { Degree 3: } 16.1 \% \\
\text { Degree } 4: 5.0 \% \\
\text { Degree 5: } 0.9 \% \\
\text { Don't know: } 1.3 \% \\
\text { (n.a.: } 0.7 \% \text { ) }\end{array}$ & $\begin{array}{c}n=993 \\
n=540 \\
n=60 \\
n=160 \\
n=161 \\
n=50 \\
n=9 \\
n=13 \\
n=7\end{array}$ & $p<0.001$ \\
\hline $\begin{array}{l}\text { Hospitalization last } \\
6 \text { months }\end{array}$ & $\begin{array}{l}\text { No admission: } 75.1 \% \\
\text { Non-emergency: } 15.6 \% \\
\text { Emergency: } 7.1 \% \\
\text { (n.a.: } 2.2 \% \text { ) }\end{array}$ & $\begin{array}{c}n=202 \\
n=42 \\
n=19 \\
n=6\end{array}$ & $\begin{array}{l}\text { No admission: } 82.4 \% \\
\text { Non-emergency: } 13.5 \% \\
\text { Emergency: } 3.5 \% \\
\text { (n.a.: } 0.6 \% \text { ) }\end{array}$ & $\begin{array}{c}n=824 \\
n=135 \\
n=35 \\
n=6\end{array}$ & $p=0.023 \#$ \\
\hline $\begin{array}{l}\text { Telemedicine-- } \\
\text { technical options }\end{array}$ & $\begin{array}{c}\text { Yes: } 85.5 \% \\
\text { No: } 11.9 \% \\
\text { (n.a.: } 2.6 \% \text { ) } \\
\end{array}$ & $\begin{array}{c}n=230 \\
n=32 \\
n=7\end{array}$ & $\begin{array}{c}\text { Yes: } 92.6 \% \\
\text { No: } 4.1 \% \\
\text { (n.a.: } 3.3 \% \text { ) } \\
\end{array}$ & $\begin{array}{l}n=926 \\
n=41 \\
n=33\end{array}$ & $p<0.001 \#$ \\
\hline $\begin{array}{l}\text { Telemedicine-- } \\
\text { potential regular use }\end{array}$ & $\begin{array}{l}\text { Yes: } 48.3 \% \\
\text { No: } 43.1 \% \\
\text { (n.a.: } 8.6 \% \text { ) } \\
\end{array}$ & $\begin{array}{c}n=130 \\
n=116 \\
n=23\end{array}$ & $\begin{array}{c}\text { Yes: } 53.8 \% \\
\text { No: } 37.7 \% \\
\text { (n.a./multiple: } 8.5 \% \text { ) } \\
\end{array}$ & $\begin{array}{c}n=538 \\
n=377 \\
n=85\end{array}$ & $p=0.094 \#$ \\
\hline $\begin{array}{l}\text { Proven COVID-19 } \\
\text { Infection }\end{array}$ & $\begin{array}{c}\text { Yes, with symptoms: } 3.4 \% \\
\text { Yes, without symptoms: } 2.2 \% \\
\text { No: } 93.7 \% \\
\text { (n.a.: } 0.7 \% \text { ) }\end{array}$ & $\begin{array}{c}n=9 \\
n=6 \\
n=252 \\
n=2\end{array}$ & $\begin{array}{c}\text { Yes, with symptoms: } 0.8 \% \\
\text { Yes, without symptoms: } 0.9 \% \\
\text { No: } 97.3 \% \\
\text { (n.a.: } 1.0 \% \text { ) }\end{array}$ & $\begin{array}{c}n=8 \\
n=9 \\
n=973 \\
n=10\end{array}$ & $p<0.001 \#$ \\
\hline $\begin{array}{l}\text { Vaccination against } \\
\text { COVID-19 }\end{array}$ & $\begin{array}{c}\text { Yes, already vaccinated: } 64.4 \% \\
\text { Yes, I wish to: } 27.1 \% \\
\text { Maybe: } 4.1 \% \\
\text { No: } 2.2 \% \\
\text { (n.a.: } 2.2 \% \text { ) }\end{array}$ & $\begin{array}{c}n=173 \\
n=73 \\
n=11 \\
n=6 \\
n=6\end{array}$ & $\begin{array}{c}\text { Yes, already vaccinated: } 52.3 \% \\
\text { Yes, I wish to: } 40.8 \% \\
\text { Maybe: } 4.0 \% \\
\text { No: } 2.3 \% \\
\text { (n.a.: } 0.6 \%)\end{array}$ & $\begin{array}{c}n=523 \\
n=408 \\
n=40 \\
n=23 \\
n=6\end{array}$ & $p<0.001 *$ \\
\hline
\end{tabular}

Annotations: $p$-LTC $=$ patients with professional long-term care; $n$-LTC $=$ patients without professional longterm care. $n=$ absolute number of patients. n.a. = no or multiple answers (not included in the statistical analysis); \# = Binominal comparison between those with (combined answers) and without ("no") hospitalization or technical options, telemedicine use, or infection, respectively. * Binominal comparison between those with vaccination (combined answers "yes, I wish" or "maybe") and those without ("no"). ${ }^{\circ}$ Explanation of care degrees: In Germany, the care degree is evaluated by the "Medizinischer Dienst der Krankenkassen" considering mobility, cognitive/communicative capacities, behavioral/psychiatric problems, self-sufficiency, coping with disease and therapy related issues, structuring everyday life and social contacts. Care degrees are defined as follows using a scoring system: Degree 1 = "slight impairment of independence" (score $12.5 \leq 27$ ), Degree 2: "substantial impairment of independence" ( $27 \leq 47.5)$, Degree 3: "severe impairment of independence" (47.5 $\leq 70)$, Degree 4 : "most serious impairment of independence" (70 $\leq 90)$, Degree 5: "most serious impairment of independence with special requirements regarding nursing care" (90-100). Patients with a care degree can apply for benefits of the nursing care insurance. Bold: statistically significant. 


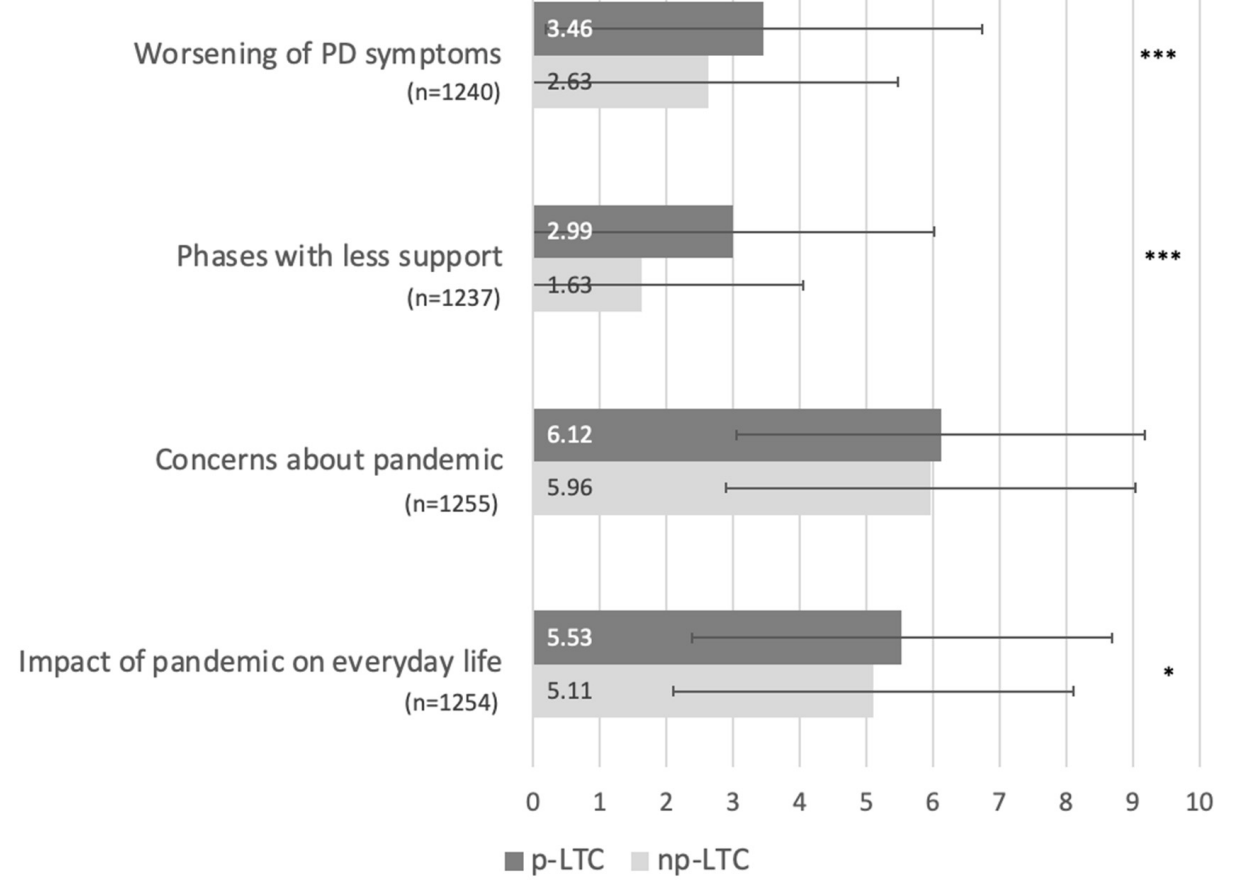

Figure 1. Evaluation of general consequences of COVID-19 pandemic in comparison between p-LTC and np-LTC group. People with Parkinson's disease (PwP) evaluated the general consequences of the pandemic on everyday life on a visual scale from 0 (not applicable/not at all) to 10 (very applicable/very much). Results are depicted as mean values with standard deviation for both groups (dark grey: PwP with professional long-term care ( $\mathrm{p}$-LTC), light grey: PwP without long-term care (np-LTC)). Significant group differences are marked with ${ }^{*}\left({ }^{*}<0.05,{ }^{* * *} p<0.001\right)$.
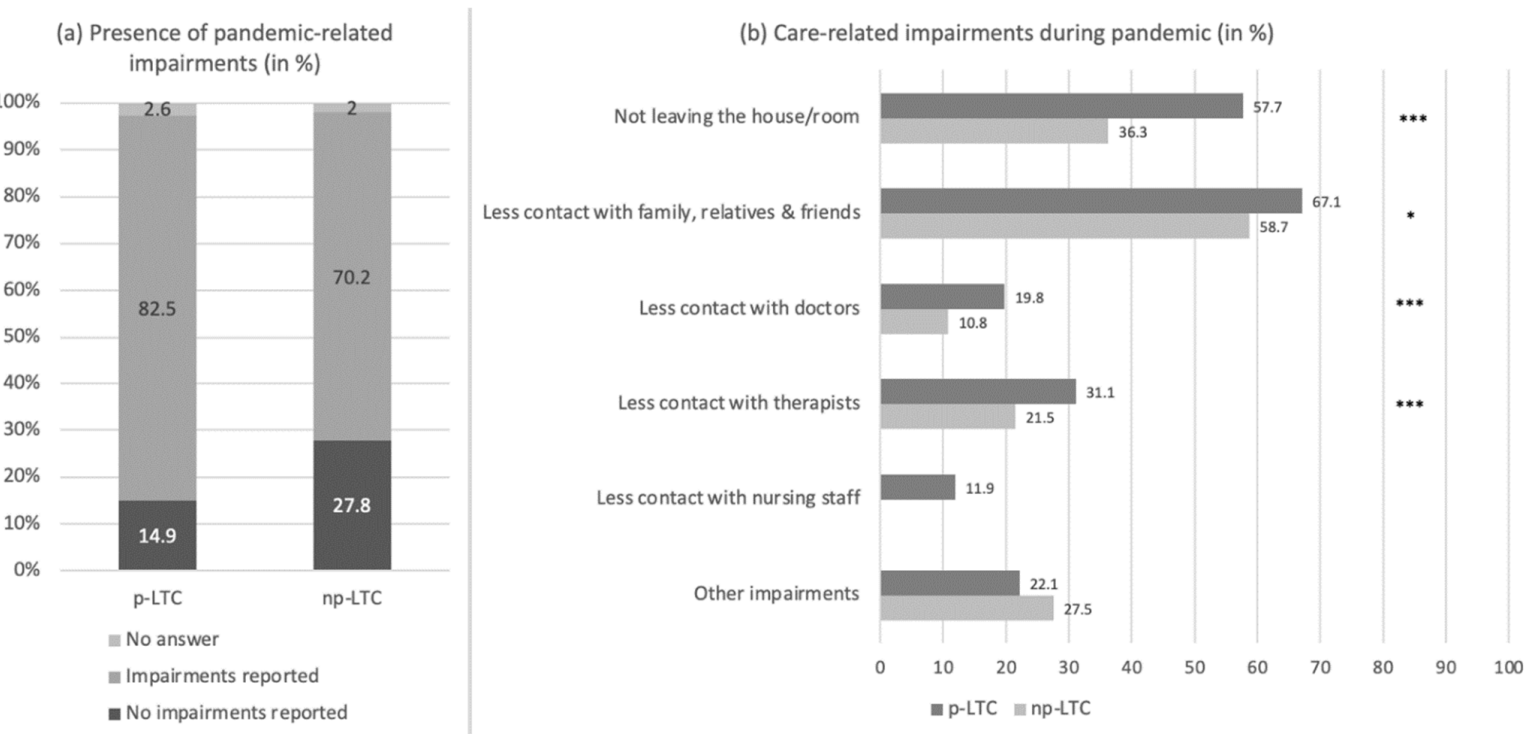

Figure 2. Specific care-related impairments during COVID-19 pandemic (in \%). (a) Percentage of people with Parkinson's disease (PwP) with or without COVID-19 pandemic-related impairments are shown for both groups with (p-LTC) and without (np-LTC) professional care. (b) Percentage of PwP reporting about certain care-related impairments: $\mathrm{p}$-LTC $=$ dark grey, np-LTC = light grey. Significant group differences are marked: ${ }^{*} p<0.05,{ }^{* * *} p<0.001$. Multiple answers were allowed here. 
PwP of both groups who indicated negative pandemic-related impact (p-LTC: $82.5 \%$, np-LTC: $70.2 \%$, see right graph (b)) also reported contact limitation with family, relatives, and friends as the major impairment, which was followed by limited options to leave the house or apartment. Interestingly, reduced contacts with doctors or nursing staff were only rarely mentioned. Again, most restrictions (leaving house, less contact with families, doctors, and therapists) were significantly more pronounced in the p-LTC group. The percentage of "other" impairments was comparable in both groups, with free text answers specifying limitations such as reduced social contacts in general, decreased cultural offerings, limited access to gastronomy, less physical activity (e.g., sports or swimming groups), or restricted interchange in the PD support groups.

\subsection{Sanitary Measures during Professional Care Sessions in the p-LTC Group}

Regarding sanitary measures during professional care sessions, as can be seen in Figure 3, results show that in the p-LTC group the best implemented measure was the nursing staff wearing masks $(85.1 \%)$, followed by hand hygiene $(68 \%)$ and room ventilation $(66.5 \%)$, whereas the PwPs' protection measures only played a minor role, with just $23.4 \%$ of them wearing a mask.

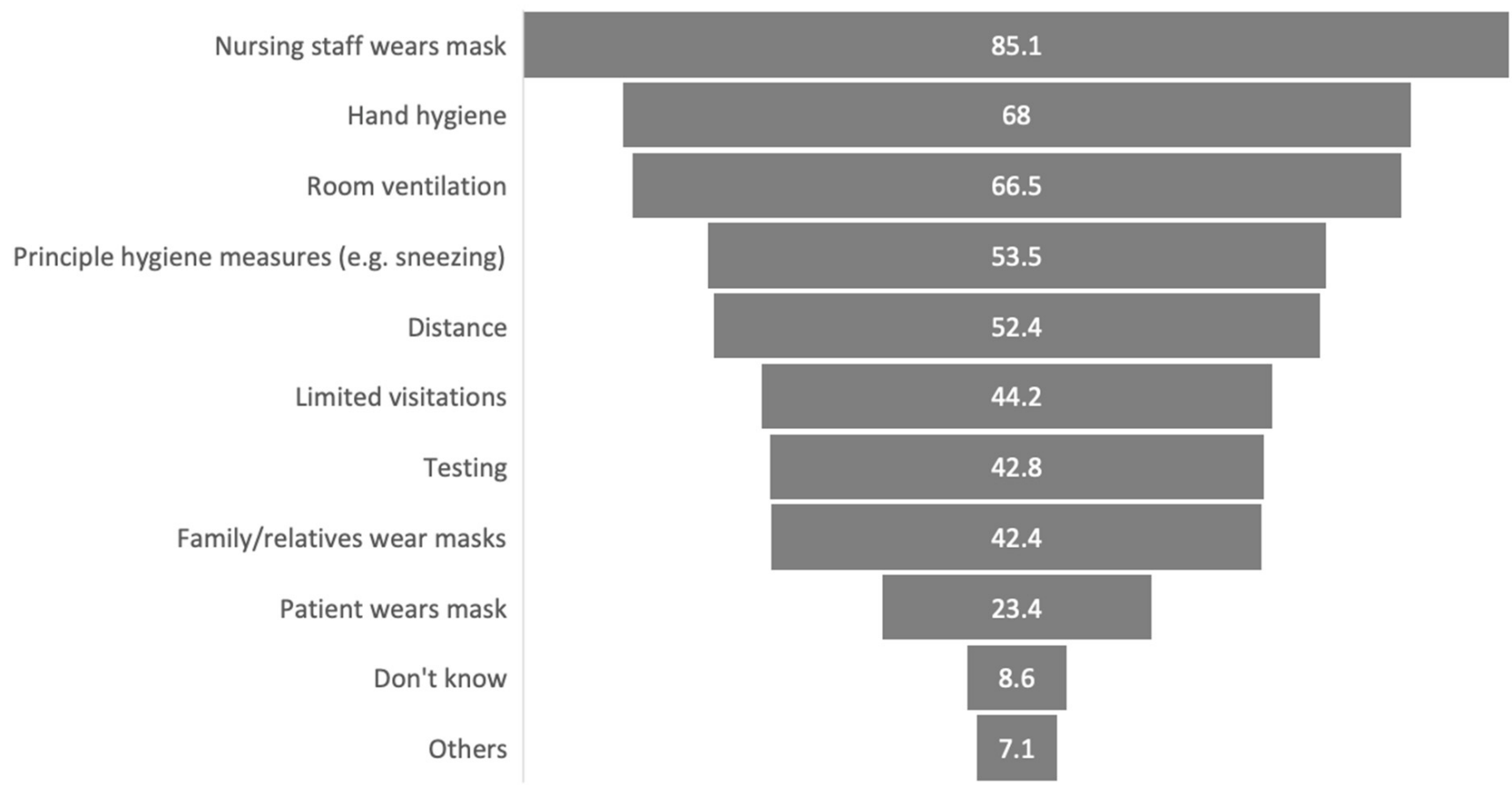

Figure 3. Sanitary measures during care sessions in the p-LTC group in \%. Sanitary measures used during professional care sessions are listed as percentage of people with Parkinson's disease with professional care $(n=269)$. Multiple answers were allowed here.

A total of $8.6 \%$ of PwP reported to not even know about the sanitary measures applied. The term "others" was mainly specified with vaccination, measuring temperature of visitors in long-term care facilities, wearing gloves, and avoiding unnecessary contacts. Furthermore, the p-LTC group felt only moderately protected by (mean $6.9(0-10) \pm$ SD 2.9) and informed about (mean $5.3(0-10) \pm$ SD 3.5) their nursing staffs' sanitary measures' concepts.

\section{Discussion}

Our study analyzed the impact of the COVID-19 pandemic on the care situation of PwP with (p-LTC) and without (np-LTC) professional long-term care. Our data were derived from the comprehensive, anonymous, nationwide Care4PD patient survey (available at [41]) that-additionally - targeted examination of the general care situation of PwP in Germany, 
as there were only very limited data available so far [44]. In particular, people with advanced PD receiving professional LTC (e.g., outpatient care services, nursing homes) only rarely participate in clinical studies and attract less scientific attention nationally and internationally [40], which leads to only sparse information on their actual care situation.

The response rate of $5.7 \%$ of this study was within the range of previous, comparable questionnaire studies of PD clientele [45-47]. Interestingly, the response rate resembled that of a recent questionnaire-based study (4.7\%) using the same distribution method via the members' journal of the German Parkinson Association but addressing a completely different topic [48].

Analysis of age, residence, and Hoehn and Yahr stages revealed that a representative group of PwP was reached with a typical mean age of $>65$ years (comparable with [44]), in both rural and urban areas and of all disease stages, although we cannot rule out that patients with atypical parkinsonism were also included in the study [49-51].

According to the official care statistics of the German Federal Bureau of Statistics from 2019 [52], from a total of 4,127,605 care service recipients ("Leistungsempfänger"), about $51 \%$ manage their care themselves or with the help of relatives. In our study, the overall rate of $\mathrm{PwP}$ with a care degree as an indirect parameter for the number of care service recipients was of $56 \%$ ( $n=705$, both groups combined) and-consistently-about $62 \%(n=440)$ of them got along without professional care.

Again, according to the care statistics [52], in the group of those recipients with an institutional care service, $41 \%$ lived in fully inpatient institutions (nursing homes) and $49 \%$ were supported by outpatient care services. In contrast, in our study, only $26.0 \%$ of PwP resided in nursing homes, whereas $62.1 \%$ received care by outpatient care services and $11.9 \%$ used outpatient $24-\mathrm{h}$ care (that is not explicitly mentioned in [52]). Furthermore, $44 \%$ of the np-LTC group had a care degree and received care insurance benefits. This could rather indicate that people with p-LTC are underrepresented here, maybe due to the method of recruiting (which we do not know, as we did not specifically target PwP in LTC facilities) or their lack of autonomy in filling out the questionnaire. Another explanation could be that PD differs from other chronic diseases with the need of p-LTC in such a way that a significant number of PwP have a slow disease progression (consistent with a long mean disease duration of 10-13 years, see Table 1) and thus may not reach the highly disabling disease stages that require professional LTC, as has been speculated before [53].

However, as it is presumed that about $5-10 \%$ of $\mathrm{PwP}$ reside in long-term care facilities [54] with - based on our knowledge-an unknown number of those receiving outpatient care services, the percentage of $21.1 \%$ PwP receiving p-LTC in our study seems to be realistic. Nevertheless, it must be mentioned that we did not ask for the specific qualification and duties of the nursing staff and thus cannot distinguish between the different care services according to the German "Sozialgesetzbuch" V and XI, such as medication control only vs. comprehensive nursing care.

As expected, the p-LTC group was older, with higher disease severity, reported a higher hospitalization rate, and had more impairments during the pandemic.

Empirically and data-based, we hypothesized that due to the pandemic PwP might have strikingly less health care assess in the inpatient sector (e.g., decreased admissions of PwP to clinics, less access to PD multimodal complex treatment and application of pump-based therapies [39]) or DBS [55]). This hypothesis was supported by our data showing that about $80 \%$ of our PwP sample reported no hospital admissions during the last 6 months of the pandemic. It is remarkable that health care access to doctors and therapists in the outpatient sector was not relevantly affected - at least for those without professional care. This indicates that the outpatient care was maintained during the pandemic crisis as a "stable pillar", potentially also thanks to individual but likewise professional-political efforts such as the "Central Corona Platform for neurologists and psychiatrists" [56] by the German professional associations for neurologists ("Berufsverband Deutscher Neurologen") and psychiatrists. This online initiative aimed at ensuring the continuation of constant patient care by offering practical and educational support for resident physicians 
during the pandemic, such as online seminars or by providing consultation, assistance, and expert information. Additionally, the use of telemedicine was recommended by the initiative to ascertain patient care during the pandemic. Potentially, telemedicine might also be an option to better reach the p-LTC clientele [57-59]. However, our data indicate that although technical options were accessible in most PwP (even those with p-LTC, who additionally might not only need technical options but also care staff support to use the technology), acceptance and use of this technique was rather low in both groups. Although telemedicine approaches have been shown to be effective $[60,61]$ and are widely recommended for PwP [16,32,62], even by the International Parkinson and Movement Disorder Society [1], our findings are congruent with previous studies documenting that even high levels of satisfaction with telemedicine did not translate into a sustained interest or use of this health care approach [2,12]. Extensive promotion of remote or virtual care modes that have been found to be as effective as in-person communication [63] or alternative offerings (e.g., conducting more house calls by medical and/or therapeutical staff, cross-sectoral approaches with PD nurse specialists as in other countries that are only rarely deployed in Germany so far [64]) should be focused on in the future.

Noteworthy, the largest impact resulted from social distancing, especially distancing from families, relatives, and friends and from feeling restricted to home/room-aspects that have been found before $[14,32]$ and that seem to increase stress levels [24,32]. In a previous study, high perceived stress in PwP was associated with lower social support [24], and COVID-19-related stressors were associated with mental health issues especially in female, highly educated people, people with advanced $\mathrm{PD}$, and those vulnerable to distancing or seeking social support [65]. Moreover, other studies documented the negative impact of the pandemic on the health and function of PwP $[2,16,18,29,65]$.

However, others found that especially family members supported the PwP during the pandemic and took care of their unmet needs, such as shopping or picking-up medication [33]. In a Danish/Swedish study, PwP ratings and written complements even suggested that there was an improvement in health-related quality of life, with the feeling that the "pressure" was gone since the beginning of the pandemic [37]. These may be some reasons why-despite the negative impact on social contacts mentioned above- $\mathrm{PwP}$ in our study somehow seemed to cope relatively well with the pandemic situation, with feeling only moderate concerns, moderate impact on everyday live, and little influence on PD symptoms during the pandemic.

Furthermore, although we generally asked for the whole COVID-19 pandemic period, the study period was within the "relaxation phase" between the second and third "pandemic wave" in Germany, with the availability of vaccination and extensive sanitary measures including rapid antigen tests that suggested to slowly "regain one's life back". All these aspects might have spread optimism amongst PwP and might have influenced our results. In our sample, until July 2021, the overall vaccination rate of $58 \%$ (64\% in those with p-LTC) was comparable with that of the general population at that time (56-62\% [66]), and vaccination is still intensely recommended by movement disorders specialists [67].

Although it seems that the pandemic-related general burden has been quite compensated for in the German PD community, our survey indicates that PwP with professional LTC were significantly more affected by the pandemic compared with those without. This was true regarding not only the general pandemic consequences (especially higher COVID19 infection rate, less support, more worsening of PD symptoms) but also with a view to specific, care-related consequences (especially less contact with beloved ones, therapists, and doctors and feeling tied to the house/apartment). Still, regarding sanitary measures, a lack of protection of self and others in this group can be recognized, and doctors and caregivers should more strictly advise their PwP to wear a mask, especially during care contacts. Nonetheless, even sanitary measures that were applied most (nursing staff wearing masks and hand hygiene) were not optimally exploited. As a limitation, we did not ask for the vaccination rate of the nursing staff (also with respect to data protection reasons), but 
this might also be a relevant sanitary measures factor. All in all, prospectively, the p-LTC clientele should be brought into focus more intensely.

\section{Conclusions}

The negative impact of the COVID-19 pandemic on the health care situation in PwP in Germany was not as severe as expected based on prior empirical impression and inpatient data, at least with respect to the outpatient sector and at a time slightly more than one year after pandemic onset. Main self-reported impairment was due to social or familial contact restrictions and isolation. However, our data suggest that PwP receiving professional long-term care are more impaired during the pandemic compared with those without and therefore should get more attention in the future by providing alternative strategies to better reach and care for them.

Supplementary Materials: The following supporting information can be downloaded at: https: / /www.mdpi.com/article/10.3390/brainsci12010062/s1, Table S1: Questionnaire.

Author Contributions: Conceptualization: O.F., M.S., A.A., R.K. and A.-M.H.; methodology: O.F., M.S., A.A. and T.M.; formal analysis: O.F.; investigation: O.F., C.K., E.B.d.M. and C.B.; writingoriginal draft preparation: O.F., M.S. and A.-M.H.; writing-review and editing: O.F., A.A., M.S., A.-M.H., R.K., C.B., T.M., C.K. and E.B.d.M.; visualization: O.F. and M.S.; supervision: M.S. and R.K.; funding acquisition: O.F. All authors have read and agreed to the published version of the manuscript.

Funding: This research was funded by the Prof. Dr. Klaus Thiemann Stiftung (no grant number available) and received grants from the Luxembourg National Research Fund (FNR) within the National Centre of Excellence in Research on Parkinson's disease [NCERPD(FNR/NCER13/BM/11264123)].

Institutional Review Board Statement: The study was conducted according to the guidelines of the Declaration of Helsinki, and the study was approved by the local Ethics Committee (Ethikkomission der Landesärztekammer Brandenburg, reference: S10(bB)/2021, date of approval: 9 February 2021).

Informed Consent Statement: Patient consent was waived due to anonymous questionnaires.

Data Availability Statement: Data are contained within this article and in Supplementary Materials.

Acknowledgments: We thank the people with Parkinson's disease for their participation and additional handwritten statements that will further help to understand and improve the care situation in the future. We also thank our cooperation partners (Deutsche Parkinson Vereinigung e.V., Deutsche Parkinson Hilfe, Bundesverband der kommunalen Senioren- und Behinderteneinrichtungen e.V., FONTIVA Unternehmensgruppe, Berufsverband Deutscher Neurologen), Josephine Green and Beate Schönwald (University Medical Center Hamburg-Eppendorf) for their support.

Conflicts of Interest: R.K. received research grants from Fonds National de Recherche de Luxembourg (FNR) as Coordinator of the National Centre for Excellence in Research on Parkinson's disease (NCER-PD) and within the PEARL Excellence Programme (FNR/P13/6682797/Krüger), the Michael J. Fox Foundation (ID: 1480), and the European Union's Horizon 2020 research and innovation program (Orchestra; Grant Agreement $\left.\mathrm{N}^{\circ} 101016167\right)$. This research was funded by the Prof. Dr. Klaus Thiemann Stiftung (no grant number available). The other authors declare no conflicts of interest. The funders had no role in the design of the study; in the collection, analyses, or interpretation of data; in the writing of the manuscript; or in the decision to publish the results.

\section{References}

1. Papa, S.M.; Brundin, P.; Fung, V.S.C.; Kang, U.J.; Burn, D.J.; Colosimo, C.; Chiang, H.L.; Alcalay, R.N.; Trenkwalder, C. Impact of the COVID-19 Pandemic on Parkinson's Disease and Movement Disorders. Mov. Disord. 2020, 35, 711-715. [CrossRef]

2. Cartella, S.M.; Terranova, C.; Rizzo, V.; Quartarone, A.; Girlanda, P. Covid-19 and Parkinson's disease: An overview. J. Neurol. 2021, 268, 4415-4421. [CrossRef]

3. Helmich, R.C.; Bloem, B.R. The Impact of the COVID-19 Pandemic on Parkinson's Disease: Hidden Sorrows and Emerging Opportunities. J. Parkinson's Dis. 2020, 10, 351-354. [CrossRef] [PubMed]

4. Antonini, A.; Leta, V.; Teo, J.; Chaudhuri, K.R. Outcome of Parkinson's Disease Patients Affected by COVID-19. Mov. Disord. 2020, 35, 905-908. [CrossRef] [PubMed]

5. Antonini, A.; Leta, V.; Teo, J.; Chaudhuri, K.R. Reply to: Concerns Raised by Publication of Antonini et al., 'Outcome of Parkinson Disease Patients Affected by COVID-19'. Mov. Disord. 2020, 35, 1298. [CrossRef] [PubMed] 
6. Raphael, K.G. Concerns Raised by Publication of Antonini et al., "Outcome of Parkinson Disease Patients Affected by Covid-19". Mov. Disord. 2020, 35, 1297. [CrossRef]

7. Artusi, C.A.; Romagnolo, A.; Ledda, C.; Zibetti, M.; Rizzone, M.G.; Montanaro, E.; Bozzali, M.; Lopiano, L. COVID-19 and Parkinson's Disease: What Do We Know So Far? J. Parkinson's Dis. 2021, 11, 445-454. [CrossRef]

8. Gruchot, J.; Kremer, D.; Küry, P. Neural Cell Responses Upon Exposure to Human Endogenous Retroviruses. Front. Genet. 2019, 10, 655. [CrossRef]

9. Bouali-Benazzouz, R.; Benazzouz, A. Covid-19 Infection and Parkinsonism: Is There a Link? Mov. Disord. 2021, 36, 1737-1743 [CrossRef]

10. Merello, M.; Bhatia, K.P.; Obeso, J.A. SARS-CoV-2 and the risk of Parkinson's disease: Facts and fantasy. Lancet Neurol. 2021, 20, 94-95. [CrossRef]

11. Sulzer, D.; Antonini, A.; Leta, V.; Nordvig, A.; Smeyne, R.J.; Goldman, J.E.; Al-Dalahmah, O.; Zecca, L.; Sette, A.; Bubacco, L.; et al COVID-19 and possible links with Parkinson's disease and parkinsonism: From bench to bedside. NPJ Parkinson's Dis. 2020, 6, 18. [CrossRef]

12. de Rus Jacquet, A.; Bogard, S.; Normandeau, C.P.; Degroot, C.; Postuma, R.B.; Dupré, N.; Miyasaki, J.M.; Monchi, O.; Martino, D.; Fon, E.A.; et al. Clinical perception and management of Parkinson's disease during the COVID-19 pandemic: A Canadian experience. Parkinsonism Relat. Disord. 2021, 91, 66-76. [CrossRef] [PubMed]

13. Brown, E.G.; Chahine, L.M.; Goldman, S.M.; Korell, M.; Mann, E.; Kinel, D.R.; Arnedo, V.; Marek, K.L.; Tanner, C.M.; et al. The Effect of the COVID-19 Pandemic on People with Parkinson's Disease. J. Parkinson's Dis. 2020, 10, 1365-1377. [CrossRef] [PubMed]

14. Yogev-Seligmann, G.; Kafri, M. COVID-19 social distancing: Negative effects on people with Parkinson disease and their associations with confidence for self-management. BMC Neurol. 2021, 21, 284. [CrossRef] [PubMed]

15. Cilia, R.; Bonvegna, S.; Straccia, G.; Andreasi, N.G.; Elia, A.E.; Romito, L.M.; Devigili, G.; Cereda, E.; Eleopra, R. Effects of COVID-19 on Parkinson's Disease Clinical Features: A Community-Based Case-Control Study. Mov. Disord. 2020, 35, 1287-1292. [CrossRef] [PubMed]

16. Falla, M.; Dodich, A.; Papagno, C.; Gober, A.; Narduzzi, P.; Pierotti, E.; Falk, M.; Zappini, F.; Colosimo, C.; Turella, L. Lockdown effects on Parkinson's disease during COVID-19 pandemic: A pilot study. Acta Neurol. Belg. 2021, 121, 1191-1198. [CrossRef] [PubMed]

17. Silva-Batista, C.; Coelho, D.B.; Júnior, R.C.F.; Almeida, L.R.; Guimarães, A.; Nóbrega, K.C.C.; Machado Sanchez, H.; Lindquist, A.R.R.; Israel, V.L.; Kanegusuku, H.; et al. Multidimensional Factors Can Explain the Clinical Worsening in People with Parkinson's Disease During the COVID-19 Pandemic: A Multicenter Cross-Sectional Trial. Front. Neurol. 2021, 12, 708433. [CrossRef]

18. Montanaro, E.; Artusi, C.A.; Rosano, C.; Boschetto, C.; Imbalzano, G.; Romagnolo, A.; Bozzali, M.; Rizzone, M.G.; Zibetti, M.; Lopiano, L. Anxiety, depression, and worries in advanced Parkinson disease during COVID-19 pandemic. Neurol. Sci. 2021, 1-8. [CrossRef]

19. Rábano-Suárez, P.; Martínez-Fernández, R.; Natera-Villalba, E.; Pareés, I.; Martínez-Castrillo, J.C.; Alonso-Canovas, A. Impulse Control Disorders in Parkinson's Disease: Has COVID-19 Related Lockdown Been a Trigger? Mov. Disord Clin. Pract. 2021, 8 , 940-943. [CrossRef]

20. Suzuki, K.; Numao, A.; Komagamine, T.; Haruyama, Y.; Kawasaki, A.; Funakoshi, K.; Fujita, H.; Suzuki, S.; Okamura, M.; Shiina, T.; et al. Impact of the COVID-19 Pandemic on the Quality of Life of Patients with Parkinson's Disease and Their Caregivers: A Single-Center Survey in Tochigi Prefecture. J. Parkinson's Dis. 2021, 11, 1047-1056. [CrossRef]

21. Suzuki, K.; Numao, A.; Komagamine, T.; Haruyama, Y.; Kawasaki, A.; Funakoshi, K.; Fujita, H.; Suzuki, S.; Okamura, M.; Shiina, T.; et al. Impact of home confinement during COVID-19 pandemic on Parkinson's disease. Parkinsonism Relat. Disord. 2020, 80, 32-34.

22. Balci, B.; Aktar, B.; Buran, S.; Tas, M.; Donmez Colakoglu, B. Impact of the COVID-19 pandemic on physical activity, anxiety, and depression in patients with Parkinson's disease. Int. J. Rehabil. Res. 2021, 44, 173-176. [CrossRef]

23. Salari, M.; Zali, A.; Ashrafi, F.; Etemadifar, M.; Sharma, S.; Hajizadeh, N.; Ashourizadeh, H. Incidence of Anxiety in Parkinson's Disease During the Coronavirus Disease (COVID-19) Pandemic. Mov. Disord. 2020, 35, 1095-1096. [CrossRef]

24. van der Heide, A.; Meinders, M.J.; Bloem, B.R.; Helmich, R.C. The Impact of the COVID-19 Pandemic on Psychological Distress, Physical Activity, and Symptom Severity in Parkinson's Disease. J. Parkinsons Dis. 2020, 10, 1355-1364. [CrossRef]

25. Yule, E.; Pickering, J.S.; McBride, J.; Poliakoff, E. People with Parkinson's report increased impulse control behaviours during the COVID-19 UK lockdown. Parkinsonism Relat. Disord. 2021, 86, 38-39. [CrossRef] [PubMed]

26. Baschi, R.; Luca, A.; Nicoletti, A.; Caccamo, M.; Cicero, C.E.; D’Agate, C.; Di Giorgi, L.; La Bianca, G.; Lo Castro, T.; Zappia, M.; et al. Changes in Motor, Cognitive, and Behavioral Symptoms in Parkinson's Disease and Mild Cognitive Impairment During the COVID-19 Lockdown. Front. Psychiatry 2020, 11, 590134. [CrossRef]

27. Del Prete, E.; Francesconi, A.; Palermo, G.; Mazzucchi, S.; Frosini, D.; Morganti, R.; Coleschi, P.; Raglione, L.M.; Vanni, P.; Ramat, S.; et al. Prevalence and impact of COVID-19 in Parkinson's disease: Evidence from a multi-center survey in Tuscany region. $J$. Neurol. 2021, 268, 1179-1187. [CrossRef] [PubMed]

28. Kapel, A.; Serdoner, D.; Fabiani, E.; Velnar, T. Impact of Physiotherapy Absence in COVID-19 Pandemic on Neurological State of Patients with Parkinson Disease. Top. Geriatr. Rehabil. 2021, 37, 50-55. [CrossRef] 
29. Shalash, A.; Roushdy, T.; Essam, M.; Fathy, M.; Dawood, N.L.; Abushady, E.M.; Elrassas, H.; Helmi, A.; Hamid, E. Mental Health, Physical Activity, and Quality of Life in Parkinson's Disease during COVID-19 Pandemic. Mov. Disord. 2020, 35, 1097-1099. [CrossRef] [PubMed]

30. Guo, D.; Han, B.; Lu, Y.; Lv, C.; Fang, X.; Zhang, Z.; Liu, Z.; Wang, Z. Influence of the COVID-19 Pandemic on Quality of Life of Patients with Parkinson's Disease. Parkinsons Dis. 2020, 2020, 1216568. [CrossRef] [PubMed]

31. Cheong, J.L.; Goh, Z.H.K.; Marras, C.; Tanner, C.M.; Kasten, M.; Noyce, A.J. The Impact of COVID-19 on Access to Parkinson's Disease Medication. Mov. Disord. 2020, 35, 2129-2133. [CrossRef]

32. Brooks, S.K.; Weston, D.; Greenberg, N. Social and psychological impact of the COVID-19 pandemic on people with Parkinson's disease: A scoping review. Public Health 2021, 199, 77-86. [CrossRef] [PubMed]

33. Hanff, A.-M.; Pauly, C.; Pauly, L.; Schröder, V.E.; Hansen, M.; Meyers, G.R.; Kaysen, A.; Hansen, L.; Wauters, F.; Krüger, R. Unmet Needs of People with Parkinson's Disease and Their Caregivers During COVID-19-Related Confinement: An Explorative Secondary Data Analysis. Front. Neurol. 2020, 11, 615172. [CrossRef] [PubMed]

34. Song, J.; Ahn, J.H.; Choi, I.; Mun, J.K.; Cho, J.W.; Youn, J. The changes of exercise pattern and clinical symptoms in patients with Parkinson's disease in the era of COVID-19 pandemic. Parkinsonism Relat. Disord. 2020, 80, 148-151. [CrossRef] [PubMed]

35. Prasad, S.; Holla, V.V.; Neeraja, K.; Surisetti, B.K.; Kamble, N.; Yadav, R.; Pal, P.K. Parkinson's Disease and COVID-19: Perceptions and Implications in Patients and Caregivers. Mov. Disord. 2020, 35, 912-914. [CrossRef] [PubMed]

36. El Otmani, H.; El Bidaoui, Z.; Amzil, R.; Bellakhdar, S.; El Moutawakil, B.; Rafai, M.A. No impact of confinement during COVID-19 pandemic on anxiety and depression in Parkinsonian patients. Rev. Neurol. 2021, 177, 272-274. [CrossRef] [PubMed]

37. HØrmann Thomsen, T.; Wallerstedt, S.M.; Winge, K.; Bergquist, F. Life with Parkinson's Disease During the COVID-19 Pandemic: The Pressure Is "OFF". J. Parkinson's Dis. 2021, 11, 491-495. [CrossRef]

38. Zipprich, H.M.; Teschner, U.; Witte, O.W.; Schönenberg, A.; Prell, T. Knowledge, Attitudes, Practices, and Burden During the COVID-19 Pandemic in People with Parkinson's Disease in Germany. J. Clin. Med. 2020, 9, 1643. [CrossRef]

39. Richter, D.; Scherbaum, R.; Bartig, D.; Gold, R.; Krogias, C.; Tönges, L. Analysis of nationwide multimodal complex treatment and drug pump therapy in Parkinson's disease in times of COVID-19 pandemic in Germany. Parkinsonism Relat. Disord. 2021, 85, 109-113. [CrossRef] [PubMed]

40. Lex, K.M.; Larkin, P.; Osterbrink, J.; Lorenzl, S. A Pilgrim's Journey-When Parkinson's Disease Comes to an End in Nursing Homes. Front Neurol. 2018, 9, 1068. [CrossRef] [PubMed]

41. Klinikum Ernst von Bergmann. Care4PD—Fragebogen für Patienten. 2021. Available online: https://www.klinikumevb.de/ fileadmin/pflege/klinikum/Neurologie/DPV_Fragebogen.pdf (accessed on 26 December 2021).

42. OCR Systeme GmbH. FormPro 3.0. Available online: https://www.ocr-systeme.de/index/formpro/ (accessed on 26 December 2021).

43. IBM. SPSS Statistics. Available online: https://www.ibm.com/de-de/analytics/spss-statistics-software (accessed on 26 December 2021).

44. Binder, S. Patientenperspektive auf die Versorgungssituation im Krankheitsbild Morbus Parkinson in Deutschland-eine Querschnittserhebung. Aktuelle Neurologie 2018, 45, 703-713. [CrossRef]

45. van der Heide, A.; Speckens, A.E.; Meinders, M.J.; Rosenthal, L.S.; Bloem, B.R.; Helmich, R.C. Stress and mindfulness in Parkinson's disease-A survey in 5000 patients. NPJ Parkinsons Dis. 2021, 7, 7. [CrossRef]

46. Naisby, J.; Amjad, A.; Ratcliffe, N.; Yarnall, A.J.; Rochester, L.; Walker, R.; Baker, K. A Survey of People with Parkinson's and Their Carers: The Management of Pain in Parkinson's. J. Geriatr. Psychiatry Neurol. 2021, 8919887211023592. [CrossRef] [PubMed]

47. Sudmeyer, M.; Volkmann, J.; Wojtecki, L.; Deuschl, G.; Schnitzler, A.; Möller, B. Deep brain stimulation-Expectations and doubts. A nationwide questionnaire study of patients with Parkinson's disease and their family members. Nervenarzt 2012, 83, 481-486. [PubMed]

48. Yenilmez, F.; Fründt, O.; Hidding, U.; Buhmann, C. Cannabis in Parkinson's Disease: The Patients' View. J. Parkinson's Dis. 2021, 11, 309-321. [CrossRef]

49. McFarland, N.R.; Hess, C.W. Recognizing Atypical Parkinsonisms: "Red Flags" and Therapeutic Approaches. Semin. Neurol. 2017, 37, 215-227. [PubMed]

50. Alster, P.; Madetko, N.; Koziorowski, D.; Friedman, A. Progressive Supranuclear Palsy-Parkinsonism Predominant (PSP-P)-A Clinical Challenge at the Boundaries of PSP and Parkinson's Disease (PD). Front. Neurol. 2020, 11, 180. [CrossRef]

51. Lachenmayer, L. Differential diagnosis of parkinsonian syndromes: Dynamics of time courses are essential. J. Neurol. 2003, 250 (Suppl. 1), I11-I14. [CrossRef]

52. Statistisches Bundesamt (Destatis). Pflegestatistik 2019. Pflege im Rahmen der Pflegeversicherung, Deutschlandergebnisse. 2020 Available online: https://www.destatis.de/DE/Themen/Gesellschaft-Umwelt/Gesundheit/Pflege/_inhalt.html (accessed on 26 December 2021).

53. Enders, D.; Balzer-Geldsetzer, M.; Riedel, O.; Dodel, R.; Wittchen, H.-U.; Sensken, S.-C.; Wolff, B.; Reese, J.-P. Prevalence, Duration and Severity of Parkinson's Disease in Germany: A Combined Meta-Analysis from Literature Data and Outpatient Samples. Eur. Neurol. 2017, 78, 128-136. [CrossRef]

54. Weerkamp, N.J.; Tissingh, G.; Poels, P.J.E.; Zuidema, S.U.; Munneke, M.; Koopmans, R.T.C.M.; Bloem, B.R. Parkinson disease in long term care facilities: A review of the literature. J. Am. Med. Dir. Assoc. 2014, 15, 90-94. [CrossRef] [PubMed] 
55. Fasano, A.; Antonini, A.; Katzenschlager, R.; Krack, P.; Odin, P.; Evans, A.H.; Foltynie, T.; Volkmann, J.; Merello, M. Management of Advanced Therapies in Parkinson's Disease Patients in Times of Humanitarian Crisis: The COVID-19 Experience. Mov. Disord. Clin. Pract. 2020, 7, 361-372. [CrossRef] [PubMed]

56. Berufsverband Deutscher Neurologen, Berufsverband Deutscher Nervenärzte, and Berufsverband Deutscher Psychiater. Zentrale Corona-Plattform für Neurologen, Nervenärzte und Psychiater. 2021. Available online: https://neurologen-psychiater-coronapraxishilfe.info/?cn-reloaded=1 (accessed on 26 December 2021).

57. Biglan, K.M.; Voss, T.S.; Deuel, L.M.; Miller, D.; Eason, S.; Fagnano, M.; George, B.P.; Appler, A.; Polanowicz, J.; Viti, L.; et al. Telemedicine for the care of nursing home residents with Parkinson's disease. Mov. Disord. 2009, 24, 1073-1076. [CrossRef] [PubMed]

58. Dorsey, E.R.; Deuel, L.M.; Voss, T.S.; Finnigan, K.; George, B.P.; Eason, S.; Miller, D.; Reminick, J.I.; Appler, A.; Viti, L.; et al. Increasing access to specialty care: A pilot, randomized controlled trial of telemedicine for Parkinson's disease. Mov. Disord. 2010, 25, 1652-1659. [CrossRef]

59. Barbour, P.J.; Arroyo, J.; High, S.; Ficher, L.B.; Staska-Pier, M.M.; McMahon, M.K. Telehealth for patients with Parkinson's disease: Delivering efficient and sustainable long-term care. Hosp. Pract. 2016, 44, 92-97. [CrossRef]

60. Vellata, C.; Belli, S.; Balsamo, F.; Giordano, A.; Colombo, R.; Maggioni, G. Effectiveness of Telerehabilitation on Motor Impairments, Non-motor Symptoms and Compliance in Patients with Parkinson's Disease: A Systematic Review. Front. Neurol. 2021, 12, 627999. [CrossRef] [PubMed]

61. Miele, G.; Straccia, G.; Moccia, M.; Leocani, L.; Tedeschi, G.; Bonavita, S.; Lavorgna, L. Digital Technologies; Web and Social Media Study Group of the Italian Society of Neurology Telemedicine in Parkinson's Disease: How to Ensure Patient Needs and Continuity of Care at the Time of COVID-19 Pandemic. Telemed. J. E Health 2020, 26, 1533-1536. [CrossRef] [PubMed]

62. van den Bergh, R.; Bloem, B.R.; Meinders, M.J.; Evers, L.J.W. The state of telemedicine for persons with Parkinson's disease. Curr. Opin. Neurol 2021, 34, 589-597. [CrossRef] [PubMed]

63. Beck, C.A.; Beran, D.B.; Biglan, K.M.; Boyd, C.M.; Dorsey, E.R.; Schmidt, P.N.; Simone, R.; Willis, A.W.; Galifianakis, N.B.; Katz, M.; et al. National randomized controlled trial of virtual house calls for Parkinson disease. Neurology 2017, 89, 1152-1161. [CrossRef]

64. Mai, T. [Status and development of the role as Parkinson Nurse in Germany-An online survey]. Pflege 2018, 31, 181-189. [CrossRef]

65. Dommershuijsen, L.J.; Van der Heide, A.; Van den Berg, E.M.; Labrecque, J.A.; Ikram, M.K.; Ikram, M.A.; Bloem, B.R.; Helmich, R.C.; Darweesh, S.K.L. Mental health in people with Parkinson's disease during the COVID-19 pandemic: Potential for targeted interventions? NPJ Parkinsons Dis. 2021, 7, 95. [CrossRef]

66. Robert Koch-Instituts. 2021. Available online: https://de.statista.com/statistik/daten/studie/1196966/umfrage/impfquotegegen-das-coronavirus-in-deutschland/ (accessed on 26 December 2021).

67. Bloem, B.R.; Trenkwalde, C.; Sanchez-Ferro, A.; Kalia, L.V.; Alcalay, R.; Chiang, H.-L.; Kang, U.J.; Goetz, C.; Brundin, P.; Papa, S.M. COVID-19 Vaccination for Persons with Parkinson's Disease: Light at the End of the Tunnel? J. Parkinson's Dis. 2021, 11, 3-8. [CrossRef] [PubMed] 